B.M.A.'s task of speaking as no other body can for the whole medical profession, while retaining proper democratic accountability. What Sir Paul suggests for the R.B. seems likely to increase accountability where it matters. Where, however, he may have underestimated the difficulties is in his approach to the autonomous committees. It is unfortunate that his report seems to suggest some unfamiliarity with all the medicopolitical complexities, but this is understandable and not necessarily a mortal defect. The scene is bedevilled by this shibboleth "autonomy." The word means literally ${ }^{3}$ : "The right of self-government." But is this what people mean when they talk about the B.M.A.'s autonomous committees? Surely their meaning is closer to what the Chairman of the Scottish Council said last week-possession of delegated authority. This better reflects the intention that these committees should go on doing those things which concern solely their own branch of practice, but refer to the Association generally when their proposals will affect their colleagues in other branches. Is this so very far from Chambers? The use of the word autonomy now tends to confuse rather than clarify relations in the Association between the various branches of the profession. Perhaps the working party charged with examining the queston may yet discover that "unification" and "federalism" are not, in their B.M.A. context, quite so far apart as may seem at first blush. "What's in a name? A rose ..."

British Medical fournal Supplement, 1972, 2, 45.

British Medical fournal Supplement, 1972, 2, 153 and (for correction of misprint) 175 .

3 Shorter Oxford English Dictionary, Third Edition. London, Oxford University Press, 1944.

\section{Haemoglobinometry in New Units}

Measurement of haemoglobin is one of the commonest tests used in medical practice. In early methods, which date from about 1900, the blood was compared against reference standards, and results were expressed as a percentage of the standard. Unfortunately the so-called standards differed from each other, so that a reading of $100 \%$ by the Haldane method as was used in Britain was different from $100 \%$ on the Sahli scale used in Europe. Accordingly, for over half a century haemoglobinometry remained haphazard and inaccurate. Nonetheless it had the advantage of easy comprehension, for if a haemoglobin of $100 \%$ was normal a patient with a haemoglobin of, say, $70 \%$ was clearly anaemic. In the last two decades the introduction of absolute haemoglobin standards and an appreciation of the fallacy of the percentage scale led to its replacement by the more accurate expression of haemoglobin concentration in $\mathrm{g} / 100 \mathrm{ml}$, with normal levels being about $13-16 \mathrm{~g} / 100 \mathrm{ml}$. Now yet another fundamental change is being proposed.

The Système International d'Unités (S.I.) was formulated in 1960 by the Comité International des Poids et Mesures because of the need for an international language in which to communicate the measurements of science and commerce. The system is an elaboration of the metric system with the metre, gramme, and litre as its basic units. Decimal fractions of the basic units are indicated by the prefixes milli $(m)$ for $10^{-3}, \operatorname{micro}(\mu)$ for $10^{-6}$, nano(n) for $10^{-9}, \operatorname{pico}(\mathrm{p})$ for $10^{-12}$, femto(f) for $10^{-15}$, and atto(a) for $10^{-18}$. This system is gaining widespread acceptance. ${ }^{1}$ The
Council of European Communities, for instance, has issued directives that it should replace all other systems of units in national legislation, and public health is mentioned explicitly in this directive. Many scientific journals, including the B.M.F., are using the recommended symbols and signs, and there is an increasing move towards its use in clinical chemistry. ${ }^{2} 3$ In support of this the International Federation of Clinical Chemistry has recommended the adoption of the system for reporting biochemical measurements, 14 and it seems likely that it will be in general use in Britain by 1973.

In order to conform with the S.I. system three types of change will be necessary. The simplest and least consequential change is that of unit, which does not entail any change in numerical value. For example, it is recommended that volumes be expressed as $\mathrm{ml}, \mu \mathrm{l}, \mathrm{nl}, \mathrm{pl}$, and $\mathrm{fl}$, and that $\mathrm{cc}, \mathrm{cmm}, \mu \mu \mathrm{l}$, and similar compounded units be abandoned. The other changes are more profound as they necessitate a change in numerical value. In order to define the patient's biochemical status in molecular terms, the mole is used as the base unit for mass, and mass concentration is expressed in moles per litre (mol/l.) or fractions thereof. The advantage of this is that it leads to a better understanding of the functional relationships of the components of a biological system. It is already widely used, for example, in the case of inorganic electrolytes, which are expressed either as "equivalents per litre" or in mmol/l. The extension of the molecular concept to other biological substances is desirable. It can be applied provided that the molecular weight of the material is known. However, when the molecular weight is not known precisely, and this is the case with most proteins, it is proposed that mass concentration should always be expressed per litre and that the present custom whereby substance concentration may be expressed arbitrarily per microlitre, millilitre, decilitre (or $100 \mathrm{ml}$ ) for various tests should be abandoned.

The effect of all this on haematology, and particularly on measurements of haemoglobin, requires serious consideration. If the recommendations by the Commission on Clinical Chemistry are to be accepted, haemoglobin will be expressed in its molar concentration. The molecular weight of haemoglobin has been defined as $64,460 .^{5}$ However, while haemoglobin occurs naturally as a tetramer containing four atoms of iron, because of its physical and chemical properties it should be considered, rather, as the monomer containing one atom of iron and having a relative molecular mass of 16,115 . Thus, on this basis, a factor of 0.621 is required to convert haemoglobin from $\mathrm{g} / 100 \mathrm{ml}$ to $\mathrm{mmol} / \mathrm{l}$, so that, for example, a haemoglobin of $14.8 \mathrm{~g} / 100 \mathrm{ml}$ is equivalent to $9.2 \mathrm{mmol} / \mathrm{l}$. By a similar conversion, $\mathrm{MCH}$ would be about $2.0 \mathrm{fmol}$ and MCHC $21 \mathrm{mmol}$ per litre.

Unfortunately some questions concerning the molecular weight of haemoglobin are still unresolved, so that the decision to use the monomer rather than the tetramer for expressing molecular weight is an arbitrary one. Moreover, as other proteins will be measured in $\mathrm{g} / \mathrm{l}$., there do not seem to be cogent arguments for making a change to the molar unit for haemoglobin. Perhaps the greatest argument against such a change is that the figure for molar concentration of haemoglobin is close to the equivalent $\mathrm{g} / 100 \mathrm{ml}$, so that serious confusion could occur and endanger the lives of patients. There is a better case for adopting the less radical change whereby haemoglobin concentration would be expressed in $\mathrm{g} / 1$. A haemoglobin of $15 \mathrm{~g} / 100 \mathrm{ml}$, for example, would then become $150 \mathrm{~g} / \mathrm{l}$., MCH $32 \mathrm{pg}$ and MCHC $340 \mathrm{~g} / 1$. These alternative proposals are 
rational and in keeping with the principles of the S.I. system.

Whatever decisions are taken by the international bodies concerned, they must find willing acceptance by national professional bodies and, even more important, by the individual physicians who will be directly affected in practice. In some countries haemoglobinometry is performed by clinical chemists in some laboratories and by haematologists in others. The confusion which could follow if different conventions are adopted by the two disciplines is disturbing, and its possibility points to the need for universal agreement on whatever convention is adopted. Any change should be co-ordinated among the different specialties and by all laboratories in each country.

Whatever changes are made will be far-reaching, requiring recalibration of apparatus and new report forms as well as making it necessary for doctors and laboratory technicians to become conversant with an entirely new set of values to replace those with which they are familiar. Such changes should not be undertaken lightly. For this reason the International Committee for Standardization in Hematology is sponsoring a series of discussions at international congresses during the next few months ${ }^{6}$ to ensure that haematologists become conversant with the proposals, and have ample opportunity to be involved with the decisions for change, if indeed change there must be.

1 Dybkaer, R., and Jofgensen, K.,Quantities and Units in Clinical Chemistry Copenhagen, Munskaard, 1967

Royal College of Pathologists Working Party, fournal of Clinical Pathology, $1970,23,818$

Broughton, P. M. G.,Quantities and Units in Clinical Biochemistry, Bulletin No. 20. London, Association of Clinical Biochemists, 1970

- Dybkaer, R., in Standard Methods of Clinical Chemistry, 1970, 6, 223.

5 International Committee for Standardization in Hematology, British, Fournal of Haematology, 1967, Supplement 13, 71 .

6 International Committee for Standardization in Haematology Working Party on Quantities and Units, 1972.

\section{Supersonic Radiation Risks}

Concorde in all its aspects is a recurring theme in public discussion. Its possible effects on the economy, on the environment, and on health are all debated. Among the main problems deserving study are those of noise and radiation.

As we go higher so the shield presented by the atmosphere against galactic and solar radiation decreases. At sea level we have the equivalent of $3 \mathrm{ft}(90 \mathrm{~cm})$ of lead roof over our heads. At the altitudes where subsonic airliners fly, $37,000-40,000 \mathrm{ft}(11,000-12,000 \mathrm{~m})$, it is equivalent to 7 in $(18 \mathrm{~cm})$ of lead, and at supersonic altitudes, 56,000-60,000 $\mathrm{ft}(17,000-18,000 \mathrm{~m})$, about $2 \frac{1}{2}$ in of lead. The steady-state radiation burden of free space is about 17 mrems per day, 12 and reviews ${ }^{3-5}$ have indicated that about 0.6-1 mrem per hour is a representative dose for passengers at $58,000 \mathrm{ft}(17,500 \mathrm{~m})$ and fairly high latitudes. F. J. Ensell ${ }^{6}$ has already reported that these estimates are in fact being confirmed. These doses must be considered in comparison with a background dose of 120 mrems per year in London, about 300 mrems in Aberdeen, and 2,000 mrems in Kerala State in India, as well as other sources of radiation in our modern life. A person very close to a colour television set is subjected to 0.5 mrems per hour. A mass miniature radiography chest $x$-ray examination on an old set may give 10 mrems, and other medical procedures make considerable additions to our personal totals of radiation.

For the average passenger, therefore, a three-hour trip in a Concorde seems relatively harmless, but the snag is that solar flares do occur, though relaitively rarely. ${ }^{7}$ During a flare the radiation dose at a cruising level of about $56,000 \mathrm{ft}$ $(17,000 \mathrm{~m})$ rapidly increases. For instance, a flare in 1956 gave a calculated dose rate of about 2 rads per hour at $60,000 \mathrm{ft}(18,000 \mathrm{~m}) .89$

Adequate warning must therefore be available to the aircrew in the event of a solar flare. ${ }^{10}$ Ground-based warnings will not be good enough because of rapid deterioration in telecommunications and therefore the aircraft itself must carry detector equipment. If the detector is unserviceable, the aircraft will not be allowed to operate at altitudes for supersonic cruising. Such equipment ${ }^{11}$ is fitted to the Concordes. Ensell ${ }^{6}$ has indicated that it is returning values close to predicted postulates. If a warning of high-dose radiation becomes operative, the Concorde can descend rapidly to a safe altitude without inconveniencing the passengers.

Provided the detector is operative, the captain takes note of it, and can descend, the risk to patients from radiation is negligible, and doctors can reassure inquirers. Moreover, the chance of a solar flare occurring during an individual journey is statistically very low.

\footnotetext{
1 Berry, C. A., Aerospace Medicine, 1970, 41, 500.

Mandrovsky, B. N., Aerospace Medicine, 1971, 42, 172

McNaughton, I. I., Royal Aircraft Establishment Technical Report 68286 , December 1968.

Fuller, E. W., and Day, B., International Congress on Protection against Accelerator and Space Radiation. Geneva, CERN, 1971

${ }^{5}$ Buley, L. E., Aerospace Medicine, 1969, 40, 1134

6 Ensell, F. J., British Medical fournal, 1971, 4, 362.

Report of the I.C.R.P. Task Group on the Biological Effects of High Energy Radiations, Health Physics, 1966, 12, 209.

${ }^{8}$ Davisson, P. J. N., The Cosmic Ray Environment of Supersonic Aircraft (Thesis) Bristol University, 1967

${ }^{9}$ Fuller, E. W., and Clarke, N. T., UKAEA/AWRE Report No. 064/68. London, H.M.S.O., 1968 .

10 International Commission for Radiological Protection, Report of Com mittee, I.C.R.P. Publication 9. Oxford, Pergamon Press, 1969.

11 Benbow, T. G., Fifth International Aerospace Instrument Symposium Cranfield, March 1968.
}

\section{Zoster and Hodgkin's Disease}

Herpes-zoster-varicella infection is commoner in patients with malignant disease than in the general population. The increase in incidence is particularly great in patients with Hodgkin's disease. ${ }^{1-3}$ Recurrent exacerbations may occur and the infections may become disseminated and cause death.

In a series of 592 patients with Hodgkin's disease at Stanford Medical Centre 91 (15.4\%) had zoster infections at some time during the course of their diseases. ${ }^{4}$ An even higher incidence $(25 \%)$ was reported over a 24-month period in 102 patients with Hodgkin's disease attending the Baltimore Cancer Research Centre. ${ }^{5}$ The incidence of this infection among patients in both centres with lymphomas other than Hodgkin's disease was less (7.1 and $8 \cdot 7 \%$ ). The infection is not so common in patients with other forms of malignant disease, including solid tumours and acute leukaemia, though it appears to be rather commoner than in the general population. Impairment of the patient's resistance by other disease, splenectomy, radiotherapy, and chemotherapy all predispose to infection. The defect in cellular immunity characteristic of Hodgkin's disease is thought to predispose especially to the development of this .}

